\title{
Propeller-Like Nanorod-Upconversion Nanoparticle Assemblies with Intense Chiroptical Activity and Luminescence Enhancement in Aqueous Phase
}

\author{
Xiaoling Wu, Liguang Xu, Wei Ma, Liqiang Liu, Hua Kuang, * Nicholas A. Kotov, \\ and Chuanlai $\mathrm{Xu}$
}

Chiral assemblies are currently one of the most dynamic research fields ${ }^{[1]}$ due to their wide application in biosensing, ${ }^{[2]}$ and chiral catalytic, ${ }^{[3]}$ as well as photonic devices. ${ }^{[4]}$ The conformation organization of the building blocks determines the functionalities of the assemblies, especially the optical properties. ${ }^{[5]}$ There are now chiroptical nanoassemblies with helices, ${ }^{[6]}$ pyramids, ${ }^{[7]}$ scissor-like nanoparticle (NP) pairs, ${ }^{[2 a, 8]}$ and other superstructures, ${ }^{\left[{ }^{[9}\right.}$ which are composed of supramolecular polymers, ${ }^{[10]}$ metal NPs, ${ }^{[1 \mathrm{~b}, 2 \mathrm{a}, 11]}$ semiconductor NPs, ${ }^{[12]}$ carbonaceous nanomaterials, ${ }^{[13]}$ and nanocomposites. ${ }^{[9 \mathrm{c}, 14]}$ Some studies have also reported propeller-like chiral structures at the molecular level for organic complexes..$^{[5,15]}$ However, to date, there are no reports on propeller-like chiral assemblies at the nanoscale. Due to their scale and strong electron polarizability of inorganic compounds, ${ }^{[6 c, 11]}$ metal nanomaterials-mediated assemblies can give rise to intense circular dichroism (CD) at visible or near infrared wavelengths. The majority of the current research is focused on the plasmonic chiral nanomaterials. ${ }^{[1 b, 2 a, 6 c, 11,16]}$ Other studies have been performed on the plasmon-exciton coupling between metal nanomaterials and semiconductor NPs or chiral molecules. ${ }^{[9 a, 12]}$ To date, there are few reports on the chiral assembly of metal-upconversion nanostructures and their chiral mechanism is not clear, although multiparticle assemblies reporting upconversion nanoparticles (UCNPs) have been reported. ${ }^{[7 c, 14,17]}$

Lanthanide-doped luminescence upconversion nanomaterials can emit higher energy light than the excitation source. ${ }^{[2 c]}$

Dr. X. Wu, Dr. L. Xu, Dr. W. Ma, Dr. L. Liu,

Prof. H. Kuang, Prof. C. Xu

State Key Lab of Food Science and Technology

Jiangnan University

Wuxi, Jiangsu 214122, P. R. China

E-mail: kuangh@jiangnan.edu.cn

Dr. X. Wu, Dr. L. Xu, Dr. W. Ma, Dr. L. Liu,

Prof. H. Kuang, Prof. C. Xu

International Joint Research Laboratory

for Biointerface and Biodetection and School of Food Science

and Technology

Jiangnan University

Wuxi, Jiangsu 214122, P. R. China

Prof. N. A. Kotov

Department of Chemical Engineering

University of Michigan

Ann Arbor, MI 48109-2136, USA

DOI: 10.1002/adma.201601261
Compared with the traditional down-conversion luminescence materials, they have a narrower band emission, longer fluorescence lifetime, and are nontoxic, which has made them promising luminescent materials in the biomedical field, ${ }^{[2 d, 18]}$ in areas such as biological imaging, ${ }^{[19]}$ and in cancer diagnosis and treatment. ${ }^{[20]}$ However, the conventional luminescence efficiency of lanthanide-doped luminescence upconversion nanomaterials does not exceed 1\%, which restricts their widespread use in the fields of biomedical science and photonic devices. ${ }^{[2 c, 20 a, 21]}$ It is known that the plasmonic resonance coupling of metal nanomaterials can enhance the luminescence of fluorescent dyes $^{[1 \mathrm{~d}, 22]}$ and NPs. ${ }^{[23]}$ Enhancement of UCNP light emission upon assembly with plasmonic NPs or nanorods is also possible. ${ }^{[2 c, 21,24]}$ However, the plasmon-enhanced upconversion luminescence has been studied for rigid solid metal supports. While this is interesting for electro-optical devices, both biological imaging and diagnostics ${ }^{[2 \mathrm{c}, 24 \mathrm{~d}, \mathrm{e}]}$ require UCNP-plasmon systems to be dispersible in biological fluids, which has not been realized so far. An additional consideration regarding the significance of such systems is that optical properties of the deformable colloids involving plasmonic NPs can be strongly dependent on their geometry, which can be utilized for biomedical purposes. ${ }^{[1 \mathrm{~b}, 2 \mathrm{a}, 16,25]}$ As we and other scientists in this field learned recently, even seemingly minor changes in the geometry of such assemblies are expected to strongly affect rotatory optical activity. ${ }^{[1,26]}$

In this study, we fabricated gold nanorod (NR)-UCNP tetramers in solution by adopting the DNA-driven selfassembly strategy to overcome the above-mentioned obstacles. By choosing specific building blocks-i.e., lengths of DNA sequences, aspect ratios of NRs, and sizes of UCNPs-the nanoscale engineered tetramers possessed strong and tailorable chiral activity in the visible region. Tuning the distance between the UCNP and NRs allowed us to realize the enhancement of upconversion luminescence with a 21.3-fold increase in aqueous solution. We also observed that these tetramers have propeller-like geometry that gave rise to strong chiroptical activity. In addition to having fundamental importance as an analog of propeller-like chiral molecules known from coordination chemistry, the chiral geometry of such systems makes possible the attomolar DNA detection with two-model capabilities.

Chiral tetramers were assembled from NRs and UCNPs functionalized with complementary DNA (see Experimental Section). Preferential binding of thiol-terminated DNA to the end facets of NRs allowed for end site blocking of the presynthesized NRs with a molar ratio of helper DNA to NRs of 
$\approx 80$. ${ }^{[2 a, 27]}$ The subsequent addition of thiolated DNA (DNA1) led to attachment to the side facets of NRs, with a molar ratio of 1:1 for DNA1 to NRs. To protect the NRs from excessive DNA modifications and make them stable for the hybridization system, thiolated polyethylene glycol (PEG) was added to the solution at a ratio of 200 (PEG to NR-DNA1). ${ }^{[2 a]}$ Simultaneously, the maleimide-PEGylated UCNPs (Yb/Er-doped $\mathrm{NaGdF}_{4}$ NPs) were modified with the complementary thiolated DNA sequence (DNA2) due to the classic thiol-maleimide "click" reaction, ${ }^{[28]}$ and the molar ratio of DNA2 strands to UCNPs was $\approx 3$, denoted as UCNP-DNA2. To obtain the tetramers, a $33 \%$ excess of the DNA-modified NRs was intentionally maintained; the added molar ratio was fourfold that of the conjugated UCNPs. The variation in building blocks brought about the finely controlled construction of the expected NR-UCNP tetramer assemblies, denoted as AUT (Figure 1a).

To study the chiroplasmonic properties of the tetramers, $20 \pm 2.7 \mathrm{~nm}$ UCNPs $\left(\mathrm{UCNP}_{20}\right)$ and a longitudinal plasmon band $\left(\lambda_{\mathrm{L}}\right)$ of $750 \mathrm{~nm}$ for NRs (average length $50.2 \pm 2.1 \mathrm{~nm}$ and an aspect ratio of 3.3 , denoted as $N_{750}$ ) were used as building blocks for the nanoassemblies, with 30 base pairs (bp, about $10 \mathrm{~nm}$ ) of DNA sequence (Figure S1 and Table S1, Supporting Information). DNA hybridization led to the formation of tetramers $\left(\mathrm{AUT}_{750}\right)$, and the corresponding NR-UCNP assemblies were identified by transmission electron microscopy (TEM, Figure 1c and Figure S2, Supporting Information) and cryo-TEM tomography (Figure $1 \mathrm{~d}$ and Figure S3, Supporting Information). Their formation was also confirmed by dynamic light scattering measurements (DLS, Figure S4a, Supporting Information). The average hydrodynamic diameter $\left(D_{\mathrm{h}}\right)$ of the NR-UCNP tetramers was $86 \pm 3.2 \mathrm{~nm}$, without larger aggregations. As a control, the DLS curve of the mixture of NRs and UCNPs was also measured, and showed a very broad peak in the range of $15-100 \mathrm{~nm}$. The $\lambda_{\mathrm{L}}$ band of the tetramers experienced a small blue shift of about $6 \mathrm{~nm}$ after the assembly, whereas the transverse peak changed very little, probably due to the large distance between the NRs, which led to weak coupling of transverse plasmons (Figure 2b). ${ }^{[29]}$

As seen from the CD spectra in Figure 2a, the tetramers revealed $\mathrm{CD}$ bands in the ultraviolet (UV) section of the spectrum (200-250 nm) attributed to the DNA bridges. ${ }^{[6 a]}$ Concurrent with the formation of tetramers, a strong increase in chiroptical activity in the plasmonic region $(300-800 \mathrm{~nm})$ of the spectrum was observed (Figure 2a). In relation to other NR assemblies, the CD signal of the tetramers displayed a bisignate shape in the spectrum between the $\lambda_{\mathrm{L}}$ from 600 to $800 \mathrm{~nm} \cdot{ }^{[2 \mathrm{a}, 6 \mathrm{c}]}$ The spectral "wave" for $600-750 \mathrm{~nm}$ was negative $\left(-32.7 \mathrm{mdeg}, \lambda_{\mathrm{L}} 713 \mathrm{~nm}\right)$, and was positive for $750-800 \mathrm{~nm}$ (32.9 mdeg, $\lambda_{\mathrm{L}} 776 \mathrm{~nm}$ ). ${ }^{[30]}$ A new CD peak in the $280-380 \mathrm{~nm}$ spectral window appeared with the assembly of tetramers, and was assigned to the absorption of UCNPs, consistent with their UV-vis spectra (Figure 2b). The chiral anisotropy factor, g, of the assembled tetramers reached $1.06 \times 10^{-2}$. As a comparison, the DNA-conjugated NRs and UCNPs showed strong chiroptical activity in the UV region (200-250 $\mathrm{nm}$ ). However, all the tested permutations of modified and unmodified starting NPs (NRs and UCNPs), exhibited weak CD, if any, bands at $250-800 \mathrm{~nm}$, in agreement with previous reports (Figure 2a). ${ }^{[8,31]}$

In order to better understand the mechanism of rotatory optical activity of the NR-UCNP assemblies, tetramers with their various geometries and various constituent building blocks were assembled. Taking into consideration that plasmonic
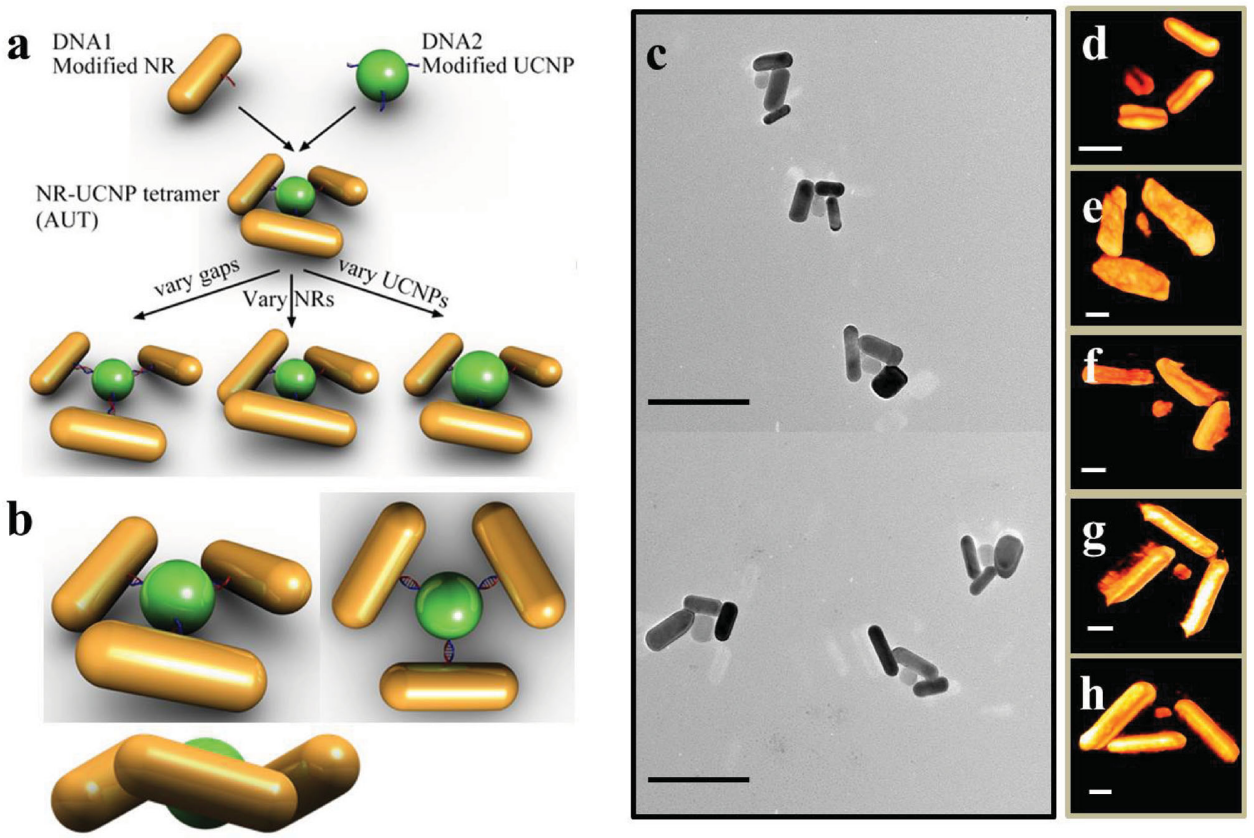

Figure 1. Structural characteristics of NR-UCNP tetramer assemblies (AUT). a) Schematic illustration for the assembly. b) The geometric structure illustrations of the tetramer. The illustrations are the front view (upper left), top view (upper right), and the side view (lower left), respectively. Representative c) TEM images and $d-h$ ) cryo-TEM tomographic reconstructions of NR-UCNP tetramer assembly. The different longitudinal absorption peak of NR was c,d) $750 \mathrm{~nm}$, e) $700 \mathrm{~nm}$; f) $800 \mathrm{~nm}$; g) $850 \mathrm{~nm}$; and h) $900 \mathrm{~nm}$, respectively; scale bar in c) and d-h) is 100 and $20 \mathrm{~nm}$, respectively. 

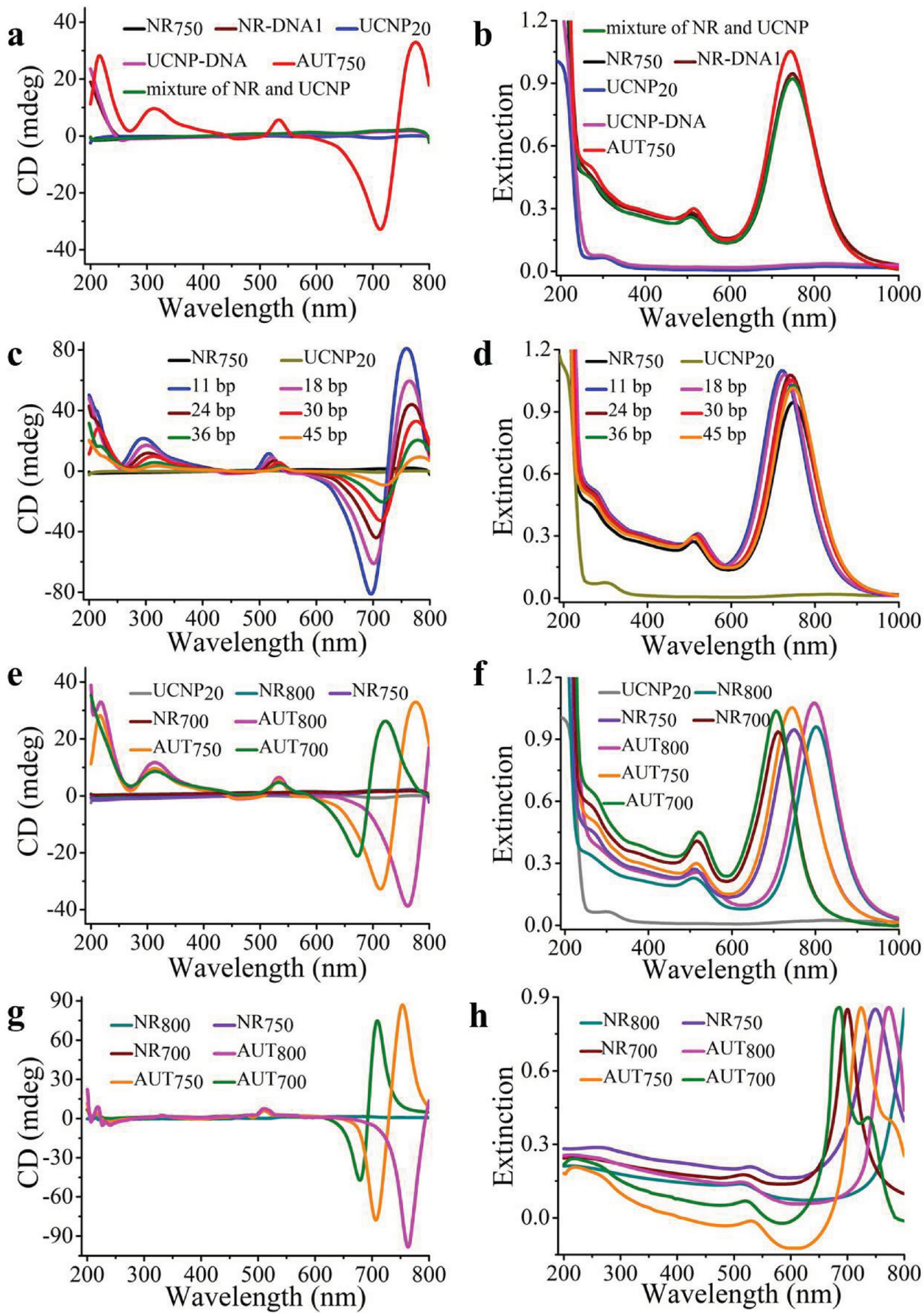

Figure 2. Chiroptical activities of the NR-UCNP tetramer assemblies. a,c,e) The experimental CD and b,d,f) UV-vis extinction spectra for NR-UCNP tetramer assembly with different lengths of $c, d)$ DNA sequences, and e,f) different longitudinal absorption of NRs and a,b) their controls. The g) theoretical CD and h) UV-vis extinction spectra of NR-UCNP tetramer and their starting NRs. The NR-UCNP tetramers were assembled with 30 bp of DNA sequence, $20 \mathrm{~nm}$ of UCNP, and the longitudinal absorption peak of NR of 700, 750, and $800 \mathrm{~nm}$.

coupling strongly depends on the distance between the plasmonic particles, ${ }^{[32]}$ we first studied the chiral optical activity of the tetramers assembled with varying lengths of DNA sequence $(11,18,24,30,36,45 \mathrm{bp})$. From the spectral measurements in Figure 2c, all the CD curves possessed similar spectral waves, with a bisignate signal for plasmonic bands at $600-800 \mathrm{~nm}$. As the DNA length decreased from 45 to $11 \mathrm{bp}$, the $\lambda_{\mathrm{L}}$ of the
CD bands significantly shifted to blue by 23 and $22 \mathrm{~nm}$ for the positive and negative part, respectively. This blue-shift of the CD spectra was in good agreement with the UV-vis spectra, although the latter showed a smaller blue shift (about $18 \mathrm{~nm}$, Figure $2 \mathrm{~d}$ ). Synchronously, CD signals showed a progressive increase in amplitude from +9.3 to +80.9 mdeg along with a shorter DNA sequence. The $\mathrm{g}$-factor value reached $2.1 \times 10^{-2}$, 
which was much higher than the molecular system $\left(10^{-3}-10^{-5}\right)$ and comparable to the highest obtained for NP assemblies reported so far. ${ }^{[8,33]}$

In addition to alterations in the length of the DNA strands, NRs with different $\lambda_{\mathrm{L}}$ absorption were also investigated. Another two sets of NRs, with $\lambda_{\mathrm{L}}$ absorption of $700 \mathrm{~nm}$ (aspect ratio of 2.6) and $800 \mathrm{~nm}$ (aspect ratio of 3.7), were also chosen for tetramer assembly. These tetramers were denoted as $\mathrm{AUT}_{700}$ and $\mathrm{AUT}_{800}$, respectively (Figure 1e,f and S5-S8, Supporting Information). The average $D_{\mathrm{h}}$ value of the tetramers increased from $75.3 \pm 2.1$ to $101 \pm 6.7 \mathrm{~nm}$ as the $\lambda_{\mathrm{L}}$ absorption increased from 700 to $800 \mathrm{~nm}$ (Figure S4b, Supporting Information). This change in $D_{\mathrm{h}}$ correlated with the statistical size measurements from the TEM images (Figures S5 and S6, Supporting Information). A strong chiroplasmonic response was observed with varying $\lambda_{\mathrm{L}}$ absorption of starting NRs. The plasmonic CD spectra displayed a marked red shift $(89 \mathrm{~nm}$, at the negative peak), corresponding to that of the absorption changes (Figure 2e,f). Increased $\lambda_{\mathrm{L}}$ of starting NRs (from 700 to $800 \mathrm{~nm}$ ) led to stronger CD intensity, with an absolute CD value from 21.2 to 38.7 mdeg. These results demonstrate that chiroptical tetramers can be constructed and engineered by adjustment of the DNA sequence and plasmonic absorption of NRs, and the largest $g$-factor value occurred at tetramer with $11 \mathrm{bp}$ of the DNA sequence, $\lambda_{\mathrm{L}}$ absorption of $750 \mathrm{~nm}$ of the NRs, and $20 \mathrm{~nm}$ UCNPs.

The 3D reconstruction of TEM tomography revealed that the three constitutive NRs in the tetramer were not parallel to each other, but had propeller-like conformations, which was likely due to the balancing of electrostatic attraction and repulsion forces, similar to many other nanoscale assemblies with biopolymers. ${ }^{[5,8,15 \mathrm{~d}, 34]}$ As expected, such geometry of the tetramers was not superimposable with their mirror images (Figure 1b,d-h; Figures S3, S7-S9, Supporting Information), which resulted in strong chiroptical activity. ${ }^{[15 a, c]}$ Similarly to the case of other chiral NPs or NRs assemblies triggered by biomolecules, ${ }^{[2 a, 8,26 a]}$ the strong chiroptical activity of propellerlike NR-UCNP tetramers was a difference of two types of enantiomers. The preference for one enantiomer as opposed to another was related to connecting DNA bridges and the general preference of charged nanoscale NRs as the conformation with minimal energy. $[2 a, 26 a]$

To further understand the origin of the tetramer's chirality, chiroptical simulations were carried out based on the frequency domain finite integral (FDFI) method, with $20 \mathrm{~nm}$ UCNPs and a $10 \mathrm{~nm}$ gap between the NRs and UCNPs. The length of the NRs was set to $50.2 \mathrm{~nm}$, and the aspect ratio was 2.6, 3.3 , and 3.7, respectively (Figure $2 \mathrm{~g}, \mathrm{~h}$ ). The simulated UV-vis spectra of the tetramers showed obvious blue-shift $(15,24$, and $27 \mathrm{~nm})$ compared with the original NRs $\left(\mathrm{NR}_{700}, \mathrm{NR}_{750}, \mathrm{NR}_{800}\right.$; Figure $2 \mathrm{~h}$ ), which was consistent with the experimental spectra (Figure 2f). The calculated CD curve exhibited a predicted bisignate signature in the $600-800 \mathrm{~nm}$ region (Figure $2 \mathrm{~g}$ ), which correlated with the $\lambda_{\mathrm{L}}$ chiral absorption of NRs as observed experimentally (Figure 2e).

Based on the above test results, the chiral optical activity of NR-UCNP tetramers was attributed to the unique propeller-like geometry of the assemblies (Figure 1b,d-h; Figures S3 and S7-S9, Supporting Information), and was confirmed by theoretical simulation (Figure 2g). In addition, it must be pointed out that other factors should be considered including plasmonplasmon coupling of the NRs. ${ }^{[6 a, 35]}$ The induced plasmonic CD originating from the electronic "imprint" of the DNA helix on electronic oscillations is likely to play a minor role based on previous studies. ${ }^{[26 a, 36]}$ It should also be pointed out that the propeller-like geometry creates a strong plasmonic field, resulting in the appearance of chiroptical bands in UCNPS (Figure 2a,c,e), which is unusual for these NPs and certainly worthy of further study.

In addition to the chiroptical activity of the NR-UCNP tetramers, the luminescence of the assemblies was investigated. The $\mathrm{AUT}_{750}$ tetramer made from $\mathrm{UCNP}_{20}, \mathrm{NR}_{750}$, and $30 \mathrm{bp}$ of DNA, was used as the initial model. Under $980 \mathrm{~nm}$ laser excitation, up-conversion luminescence (UCL) of $\mathrm{Yb} / \mathrm{Er}$ doped UCNPs was observed with the typical emission peaks located at 529, 546, and $662 \mathrm{~nm}$, which were attributed to the electronic transitions in $\mathrm{Er}^{3+}$ from ${ }^{2} \mathrm{H}_{11 / 2}$ and ${ }^{4} \mathrm{~S}_{3 / 2}$ states to the ${ }^{4} \mathrm{I}_{15 / 2}$ state, and from the ${ }^{4} \mathrm{~F}_{9 / 2}$ state to the ${ }^{4} \mathrm{I}_{15 / 2}$ state. ${ }^{[28]}$ The intensity of UCL gradually increased in the first $75 \mathrm{~min}$ as tetramers assembled matching the typical timing of DNA hybridization (Figure 3). In the following $60 \mathrm{~min}$ of the experiment, the intensity was unchanged.

The luminescence enhancement due to the formation of tetramers can be shown as $I / I_{0}$, where $I_{0}$ and $I$ represent the UCL intensity observed for original UCNPs and assembled tetramers, respectively. The UCL enhancement factors of the tetramers were $3.8,5.3$, and 6.6 for the emission bands at 529, 546, and $662 \mathrm{~nm}$, respectively (Figure $3 \mathrm{~g}$ ). In a control experiment, which indicated the significance of the assembly for UCL enhancement, we determined the change in UCL intensity after DNA modification when mixed with the NR dispersion. Without DNA bridges and tetramer formation, UCL peaks showed a slight decrease (Figure $3 \mathrm{~b}$ ). We also considered the possibility of UCL fluctuation due to the buffer conditions and $\mathrm{pH}$ value of the assembly system. As seen in Figure S10 (Supporting Information), there was no obvious variation in UCL in the tested buffer conditions and $\mathrm{pH}$ range 7.0 to 8.5 , consistent with the related $D_{\mathrm{h}}$ and electrokinetic potentials measurements (Figure S4c, Supporting Information).

To evaluate the influence of distance from the surface of NRs to UCNPs on the UCL spectra, $\mathrm{AUT}_{750}$ tetramers were assembled with different DNA strand lengths (11, 18, 24, 30, 36 , and $45 \mathrm{bp}$ ). The UCL signal was strongly quenched when the DNA sequence was shorter than $18 \mathrm{bp}$, especially with a short DNA sequence of $11 \mathrm{bp}$. The UCL quenching was ascribed to the nonradiative energy transfer (NRET) to plasmonic states in gold. ${ }^{[17,23]}$ When the distance between the NRs and NPs increased, i.e., DNA length increased to 24 and 36 bp, UCL enhancement compared with that of starting UCNPs was observed (Figure 3c). The maximum enhancement of UCL was obtained at $30 \mathrm{bp}$, after which the UCL intensity decreased to that of the original UCNPs due to low electric field intensity induced by the excess distance. ${ }^{[2 \mathrm{c}]}$

When $\mathrm{NR}_{750}$ were replaced with $\mathrm{NR}_{900}$ (Figure $3 \mathrm{~d}$ ), the strongest UCL was also obtained for 30 bp DNA bridges. The maximum enhancement factor of the assembled $\mathrm{AUT}_{900}$ tetramers was up to 8.5 and 12.4 at the bands of 529 and $546 \mathrm{~nm}$, respectively (Figure $3 \mathrm{~g}$ ). For the band at $662 \mathrm{~nm}$, the UCL 

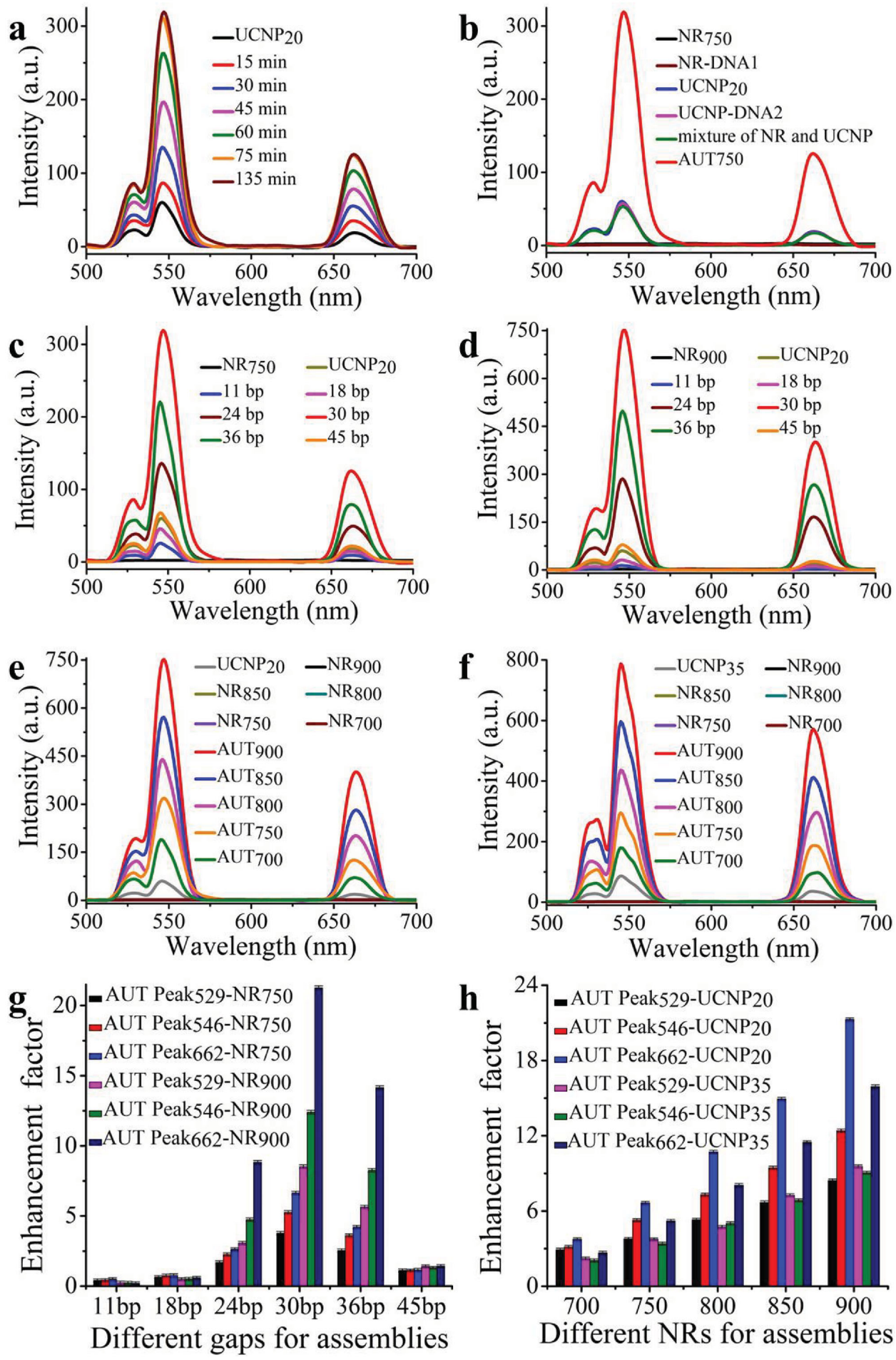

Figure 3. Up-conversion luminescence spectra of the NR-UCNP tetramer assembly and their controls under excitation at $980 \mathrm{~nm}$. a) Dynamic luminescence spectra for the assembly. b) Luminescent spectra of NR-UCNP tetramers and their controls. Assembly with different lengths of DNA sequences with the longitudinal absorption peak of NRs of c) $750 \mathrm{~nm}$, and d) $900 \mathrm{~nm}$. Assembly with different NRs, where UCNPs were e) $20 \mathrm{~nm}$, and f) $35 \mathrm{~nm}$. Luminescent enhancement factor curves of g) c, $d$, and h) e, f.

of $\mathrm{AUT}_{900}$ tetramers was 21.3-fold enhanced compared with the original UCNPs, which was approximately 3.3 times higher than the UCL of $\mathrm{AUT}_{750}$ tetramers at the same band (Figure 3g).
Further experiments were carried out to reveal the relationship between the UCL signal and the $\lambda_{\mathrm{L}}$ absorption (700, 750, 800, 850 , and $900 \mathrm{~nm}$ ) of tetramers. The UCL intensity progressively increased with increasing $\lambda_{\mathrm{L}}$ absorption (700-900 $\mathrm{nm}$ ), 
with a corresponding enhancement factor of 2.9, 3.8, 5.3, 6.7, and 8.5 at $529 \mathrm{~nm}, 3.1,5.3,7.3,9.5$, and 12.4 at $546 \mathrm{~nm}$, and 3.7, 6.6, 10.7, 15.0, and 21.3 at $662 \mathrm{~nm}$, respectively (Figure 3e,h). In these experiments, optimized enhancement was with $\mathrm{AUT}_{900}$, probably due to the closer proximity to the excitation wavelength of UCNPs $(980 \mathrm{~nm})$ for $\lambda_{\mathrm{L}}$ absorption of $\mathrm{AUT}_{900}$ compared to the others. ${ }^{[17]}$

Dependence of the UCL intensity on plasmonic resonance was further confirmed by the tetramers assembled with larger UCNPs with a diameter of $35 \pm 2.2 \mathrm{~nm}\left(\mathrm{UCNP}_{35}\right)$. The influence of varied $\lambda_{\mathrm{L}}$ absorption of NRs $(700,750,800,850$, and $900 \mathrm{~nm}$ ) on UCL was investigated based on the AUT tetramers established by $\mathrm{UCNP}_{35}$ and a DNA sequence of $30 \mathrm{bp}$. As shown in Figure 3f,h, the UCL enhancement factor was 2.2, 3.7, 4.7, 7.2, and 9.6 at $529 \mathrm{~nm}$, and 2.1, 3.4, 5.0, 6.9, and 9.1 at $546 \mathrm{~nm}$; whereas at $662 \mathrm{~nm}$, the enhancement factor was 2.7, 5.2, 8.1, 11.5, and 16.0, respectively. These were all smaller in the case of tetramers comprising $\mathrm{UCNP}_{20}$, indicating that the plasmonic-UCL enhancement was better for smaller sized UCNPs.

Here, it was clearly revealed that the maximum UCL enhancement factor occurred at a distance of $\approx 10 \mathrm{~nm}$ (30 bp of the DNA sequence), $\lambda_{\mathrm{L}}$ absorption of $900 \mathrm{~nm}$ of the NRs, and $20 \mathrm{~nm}$ UCNPs in the tested tetramers. To the best of our knowledge, this is the first time that plasmon-enhanced UCL has been successfully achieved in solution. Plasmon enhancement of UCL is ascribed to two effects: (1) increased excitation rate and efficiency arising from localized electric field enhancement by the collective oscillation coupling of NRs in the tetramers; $[17,24 \mathrm{e}]$ and (2) enhanced radiative decay rate and effective emission induced by the UCL emission coupling with plasmon resonance of NRs. ${ }^{[23,24 d, 37]}$ Electromagnetic simulations were performed to further confirm the UCL enhancement. The electric field of the $\mathrm{AUT}_{750}$ patterns assembled with $20 \mathrm{~nm}$ UCNPs, were calculated for three representative distances (3.7, 10, $15 \mathrm{~nm}$ ) from the surface of the UCNPs to NRs. As shown in Figure $4 a-c$, the electric field intensity of the tetramers gradually decreased with increasing distance $\left(6.51 \mathrm{~V} \mathrm{~m}^{-1}\right.$ for a $3.7 \mathrm{~nm}$ gap, $5.86 \mathrm{~V} \mathrm{~m}^{-1}$ for a $10 \mathrm{~nm}$ gap, $5.34 \mathrm{~V} \mathrm{~m}^{-1}$ for a $15 \mathrm{~nm}$ gap), corresponding to the larger UCL enhancement factor of tetramers with a gap of $10 \mathrm{~nm}$ (5.3-fold at $546 \mathrm{~nm})$ than a gap of $15 \mathrm{~nm}$ (1.1-fold at $546 \mathrm{~nm}$ ) (Figure 3g). In contrast, as the distance approached $3.7 \mathrm{~nm}$, the NRET (declined with inverse fourth power of localized electric field ${ }^{[17,24 a]}$ ) overwhelmingly dominated, ${ }^{[1 \mathrm{~d}]}$ therefore the UCL intensity was significantly quenched, although with a higher electric field than the above two cases. When the distance of $\mathrm{AUT}_{750}$ was set at $10 \mathrm{~nm}$, the tetramers constructed with $35 \mathrm{~nm}$ UCNPs showed lower
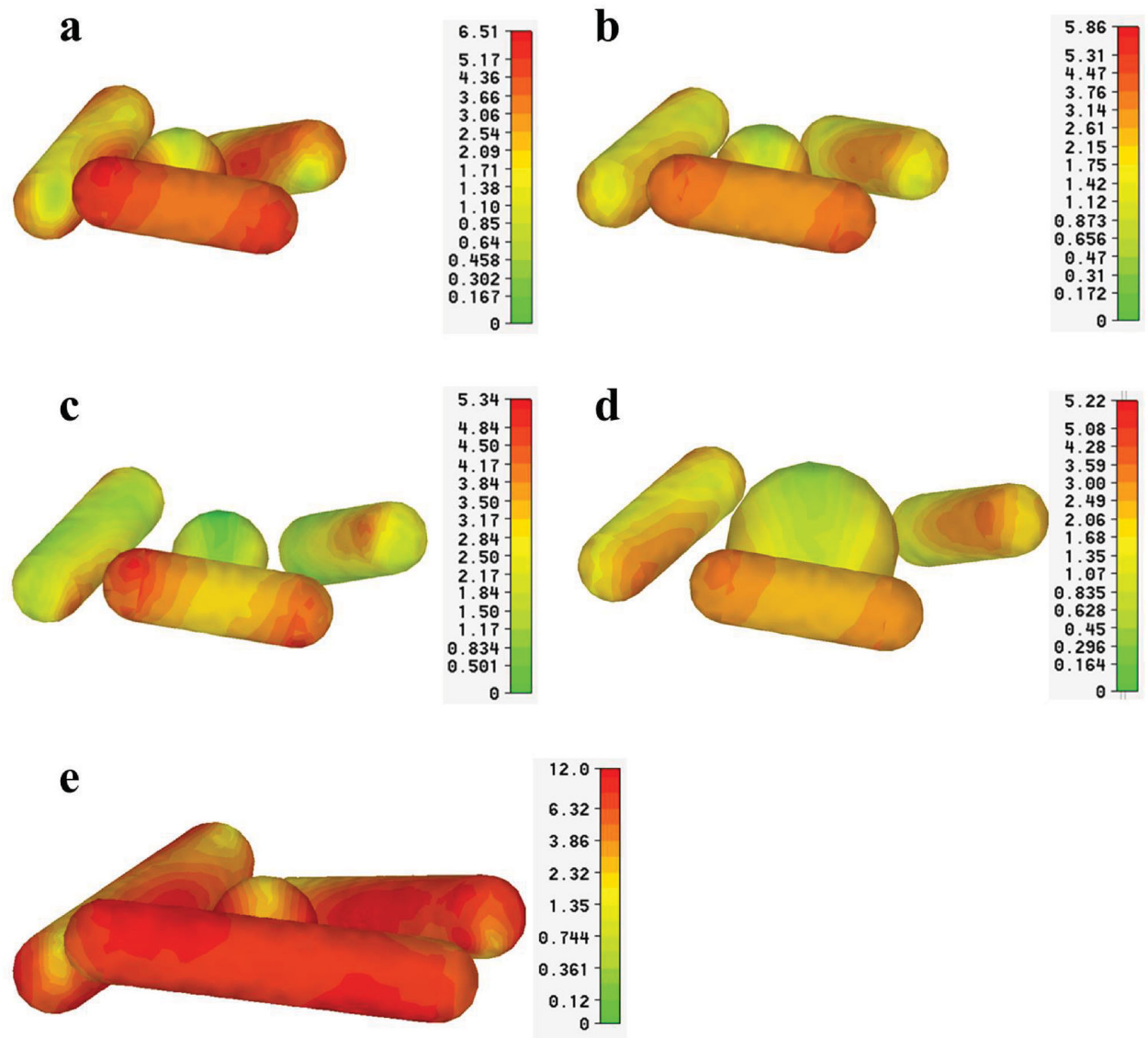

Figure 4. The electromagnetic simulations of the NR-UCNP tetramer. a,b,c) The electric field of NR-UCNP tetramer assembled with a) 11 bp, b) 30 bp, and c) $45 \mathrm{bp}$ of DNA sequences, where the longitudinal absorption peak of NR was $750 \mathrm{~nm}$, and the size of UCNP was $20 \mathrm{~nm}$. d) The electric field of NR-UCNP tetramer assembled with $30 \mathrm{bp}$ of DNA sequence, the longitudinal absorption peak of NR of $750 \mathrm{~nm}$, and $35 \mathrm{~nm}$ of UCNP. e) The electric field of NR-UCNP tetramer assembled with $30 \mathrm{bp}$ of DNA sequence, the longitudinal absorption peak of NR of $900 \mathrm{~nm}$, and $20 \mathrm{~nm}$ of UCNP. 
electric field intensity $\left(5.22 \mathrm{~V} \mathrm{~m}^{-1}\right)$ than the tetramers built with $20 \mathrm{~nm}$ UCNPs, producing a smaller UCL enhancement factor (Figures 3h, 4d). When the distance of the tetramers and the size of UCNPs were set at $10 \mathrm{~nm}$ and $20 \mathrm{~nm}$, the AUT 900 possessed a higher electric field $\left(12.0 \mathrm{~V} \mathrm{~m}^{-1}\right)$ and thus resulted in stronger UCL than $\mathrm{AUT}_{750}$ (Figures 3g, 4e).

Strong chiroptical and luminescent activity of the propellerlike assemblies enabled two-model biosensing of oligonucleotides, which improved the reliability and versatility of the method. Hepatitis A virus Vall7 polyprotein gene (HVA), was selected as the target. ${ }^{[38]}$ As illustrated in Figure 5a, NR-UCNP tetramers were fabricated with two partly complementary DNA sequences (Table S1, Supporting Information), by forming hairpin-like DNA structures between NR and UCNP. In the presence of oligonucleotide targets, hairpin-like DNA strands of the tetramers were extended, due to their specific biorecognition; and resulted in a longer gap length, which caused the reduction of both UCL and CD signal intensities. In the case of the chiroplasmonic method, $\mathrm{AUT}_{750}$ was adopted, and the calibration curve was obtained with a difference in CD intensity $\left(C D_{776 \mathrm{~nm}}-C_{713 \mathrm{~nm}}\right.$ ) (Figure $\left.5 \mathrm{~b}, \mathrm{c}\right)$. It exhibited an excellent linear response to the DNA target over the range of $3.3 \times 10^{-8}$ to $3.3 \times 10^{-5} \mathrm{nM}$. The limit of detection (LOD) was found to be 13.2 aм (Figure 5c, see Supporting Information for details). The UCL method was carried out using $\mathrm{AUT}_{750}$ (Figure 5d). The standard curve was plotted with the UCL peak intensity at $546 \mathrm{~nm}$ as the $\gamma$ axis, and the logarithmic DNA concentration as the $x$ axis. As shown in Figure 5e, the obtained LOD of 20.3 am was almost two times higher than that of the CD technique with the $\mathrm{AUT}_{750}$ assemblies, which was attributed to strong polarization rotation by the propeller-like geometry of the plasmonic nanoassemblies and bisignate characteristic of the CD spectra. ${ }^{[2 a, 8]}$ As a control, AUT $_{900}$ tetramers can also be used as a luminescence biosensor (Figure S11, Supporting Information). Besides confirming the sensitivity, we evaluated the specificity of the developed method, by using non-complementary
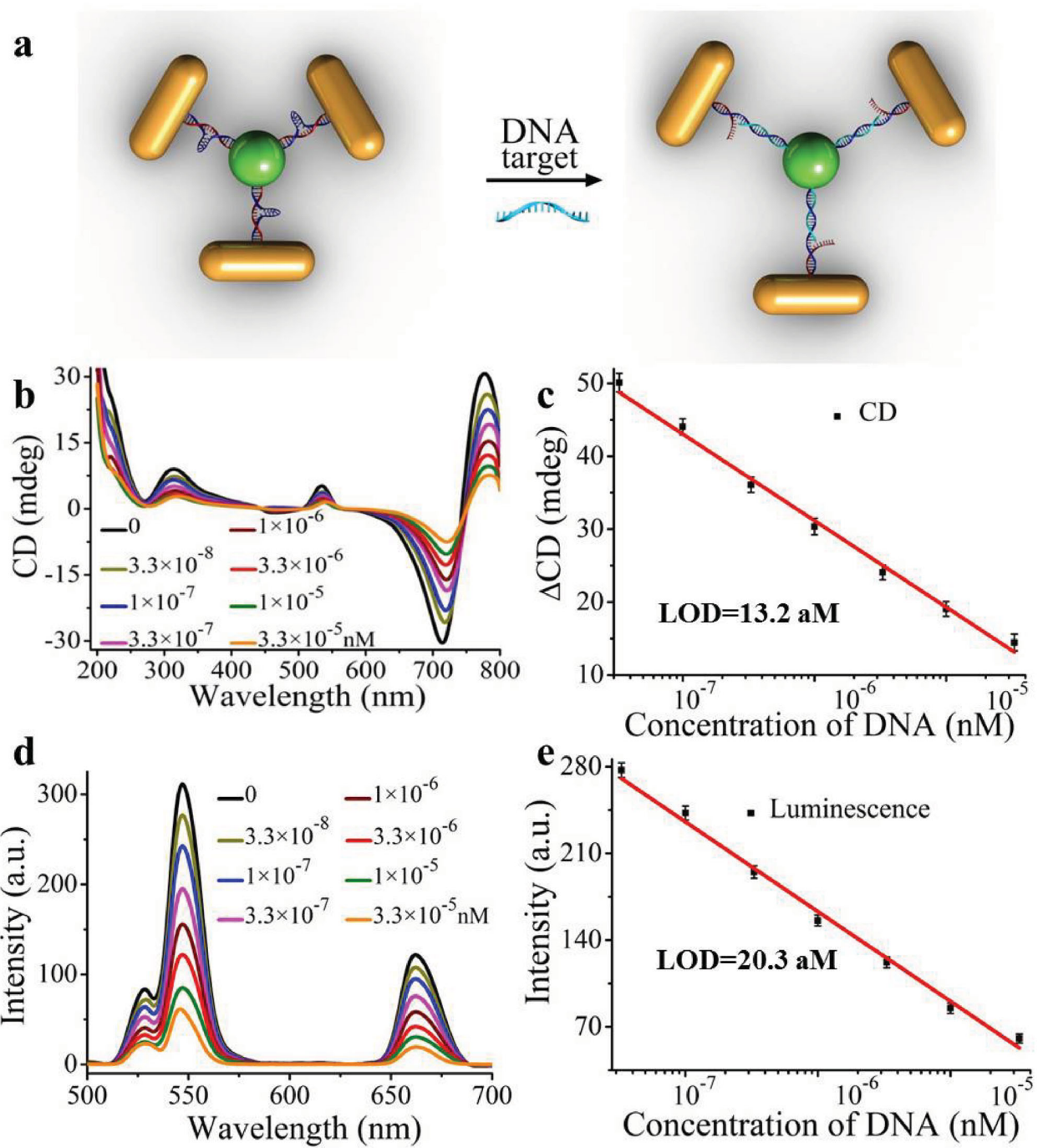

Figure 5. DNA detection by up-conversion luminescent and chiroplasmonic techniques with the NR-UCNP tetramer assembly. a) Schematic illustration for the DNA biosensing. b) The CD and d) up-conversion luminescence curves with increasing concentrations of DNA solution. C) The CD and e) upconversion luminescent calibration curves for DNA detection. The longitudinal absorption peak of NR using for assembly was 750 nm. 
hybridization DNA sequences as negative controls. The results (Figure S12, Supporting Information) showed that no obvious changes of CD signal or luminescene was observed, indicating good specificity of the biosensor. Furthermore, we also evaluated the practical application of the developed biosensor in a complex biological matrix, such as human serum. The results in Table S2 (Supporting Information) demonstrated excellent recoveries of analyte by the biosensor. In comparison with other conventional methods (such as ELISA, HPLC, plasmon resonance shift assay), therefore, the developed method possessed better sensitivity and signal-to-noise ratio, as well as more accurate quantitative determination. In addition, dual signal-detection model of the method enabled the accurate and distinct identification of cancer biomarkers, which holds promising potential for early disease diagnosis.

In summary, these propeller-like nanoscale tetramers not only offer strong chiroplasmonic and enhanced upconversion luminescent properties, but also enable DNA detection with an unusually low LOD. Looking forward, the UCNPsbased chiroplasmonic assemblies show potential for efficient bioimaging and light-guided therapy in vitro and in vivo. In addition, the ultrasensitive bioanalysis nanoplatform may also satisfy the urgent requirements for early medical diagnosis, environmental monitoring, anti-counterfeiting, and fingerprint forensics.

\section{Supporting Information}

Supporting Information is available from the Wiley Online Library or from the author.

\section{Acknowledgements}

X.W. and L.X. contributed equally to this paper. This work is financially supported by the National Natural Science Foundation of China (21471068, 31400848, 21471128, 21522102, 21503095).

Received: March 4, 2016 Revised: April 5, 2016 Published online: May 9, 2016

[1] a) J. Yeom, B. Yeom, H. Chan, K. W. Smith, S. Dominguez-Medina, J. H. Bahng, G. Zhao, W.-S. Chang, S.-J. Chang, A. Chuvilin, D. Melnikau, A. L. Rogach, P. Zhang, S. Link, P. Král, N. A. Kotov, Nat. Mater. 2015, 14, 66; b) R. Schreiber, N. Luong, Z. Fan, A. Kuzyk, P. C. Nickels, T. Zhang, D. M. Smith, B. Yurke, W. Kuang, A. O. Govorov, T. Liedl, Nat. Commun. 2013, 4, 2948; c) S. Ostovar pour, L. Rocks, K. Faulds, D. Graham, V. Parchaňský, P. Bouř, E. W. Blanch, Nat. Chem. 2015, 7, 591; d) G. P. Acuna, F. M. Möller, P. Holzmeister, S. Beater, B. Lalkens, P. Tinnefeld, Science 2012, $338,506$.

[2] a) W. Ma, H. Kuang, L. Xu, L. Ding, C. Xu, L. Wang, N. A. Kotov, Nat. Commun. 2013, 4, 2689; b) Z. Li, Z. Zhu, W. Liu, Y. Zhou, B. Han, Y. Gao, Z. Tang, J. Am. Chem. Soc. 2012, 134, 3322; c) J. Zhou, Q. Liu, W. Feng, Y. Sun, F. Li, Chem. Rev. 2015, 115, 395; d) W. Zheng, P. Huang, D. Tu, E. Ma, H. Zhu, X. Chen, Chem. Soc. Rev. 2015, 44, 1379.

[3] a) K. V. S. Ranganath, J. Kloesges, A. H. Schäfer, F. Glorius, Angew. Chem. Int. Ed. 2010, 49, 7786; b) K. Sawai, R. Tatumi, T. Nakahodo, H. Fujihara, Angew. Chem. Int. Ed. 2008, 47, 6917.

[4] a) G. Chen, H. Agren, T. Y. Ohulchanskyy, P. N. Prasad, Chem. Soc. Rev. 2015, 44, 1680; b) X. Li, F. Zhang, D. Zhao, Chem. Soc. Rev. 2015, 44, 1346.

[5] T. Nakano, Y. Okamoto, Chem. Rev. 2001, 101, 4013

[6] a) A. Kuzyk, R. Schreiber, Z. Fan, G. Pardatscher, E.-M. Roller, A. Högele, F. C. Simmel, A. O. Govorov, T. Liedl, Nature 2012, 483, 311 ; b) G. Singh, H. Chan, A. Baskin, E. Gelman, N. Repnin, P. Král, R. Klajn, Science 2014, 345, 1149; c) X. Lan, X. Lu, C. Shen, Y. Ke, W. Ni, Q. Wang, J. Am. Chem. Soc. 2015, 137, 457.

[7] a) W. Yan, L. Xu, C. Xu, W. Ma, H. Kuang, L. Wang, N. A. Kotov, J. Am. Chem. Soc. 2012, 134, 15114; b) A. J. Mastroianni, S. A. Claridge, A. P. Alivisatos, J. Am. Chem. Soc. 2009, 131, 8455; c) S. Li, L. Xu, W. Ma, X. Wu, M. Sun, H. Kuang, L. Wang, N. A. Kotov, C. Xu, J. Am. Chem. Soc. 2016, 138, 306.

[8] X. Wu, L. Xu, L. Liu, W. Ma, H. Yin, H. Kuang, L. Wang, C. Xu, N. A. Kotov, J. Am. Chem. Soc. 2013, 135, 18629.

[9] a) Z. Zhu, J. Guo, W. Liu, Z. Li, B. Han, W. Zhang, Z. Tang, Angew. Chem. 2013, 125, 13816; b) C. Tan, X. Qi, Z. Liu, F. Zhao, H. Li, X. Huang, L. Shi, B. Zheng, X. Zhang, L. Xie, Z. Tang, W. Huang, H. Zhang, J. Am. Chem. Soc. 2015, 137, 1565; c) W. Liu, Z. Zhu, K. Deng, Z. Li, Y. Zhou, H. Qiu, Y. Gao, S. Che, Z. Tang, J. Am. Chem. Soc. 2013, 135, 9659; d) C. Hao, L. Xu, W. Ma, X. Wu, L. Wang, H. Kuang, C. Xu, Adv. Funct. Mater. 2015, 25, 5816.

[10] L. Zhang, L. Qin, X. Wang, H. Cao, M. Liu, Adv. Mater. 2014, 26, 6959.

[11] S. H. Jung, J. Jeon, H. Kim, J. Jaworski, J. H. Jung, J. Am. Chem. Soc. 2014, 136, 6446 .

[12] A. Ben-Moshe, B. M. Maoz, A. O. Govorov, G. Markovich, Chem. Soc. Rev. 2013, 42, 7028.

[13] P. Deria, C. D. Von Bargen, J.-H. Olivier, A. S. Kumbhar, J. G. Saven, M. J. Therien, J. Am. Chem. Soc. 2013, 135, 16220.

[14] L.-L. Li, Y. Lu, J. Am. Chem. Soc. 2015, 137, 5272.

[15] a) F. Vera, R. M. Tejedor, P. Romero, J. Barberá, M. B. Ros, J. L. Serrano, T. Sierra, Angew. Chem. 2007, 119, 1905; b) J. Barberá, L. Puig, P. Romero, J. L. Serrano, T. Sierra, J. Am. Chem. Soc. 2006, 128, 4487; c) A. Martinez, L. Guy, J.-P. Dutasta, J. Am. Chem. Soc. 2010, 132, 16733; d) F. Grillo, V. Mugnaini, M. Oliveros, S. M. Francis, D.-J. Choi, M. V. Rastei, L. Limot, C. Cepek, M. Pedio, S. T. Bromley, J. Phys. Chem. Lett. 2012, 3, 1559.

[16] X. Shen, A. Asenjo-Garcia, Q. Liu, Q. Jiang, F. J. García de Abajo, N. Liu, B. Ding, Nano Lett. 2013, 13, 2128.

[17] A. L. Feng, M. L. You, L. Tian, S. Singamaneni, M. Liu, Z. Duan, T. J. Lu, F. Xu, M. Lin, Sci. Rep. 2015, 5, 7779.

[18] a) Y. I. Park, K. T. Lee, Y. D. Suh, T. Hyeon, Chem. Soc. Rev. 2015, 44, 1302; b) X. Liu, C.-H. Yan, J. A. Capobianco, Chem. Soc. Rev. 2015, 44, 1299; c) B. Zhou, B. Shi, D. Jin, X. Liu, Nat. Nanotechnol. 2015, 10, 924; d) X. Zhao, L. Xu, M. Sun, W. Ma, X. Wu, H. Kuang, L. Wang, C. Xu, Small 2016, DOI: 10.1002/smll.201503629.

[19] a) J.-N. Liu, W.-B. Bu, J.-L. Shi, Acc. Chem. Res. 2015, 48, 1797; b) R. Deng, F. Qin, R. Chen, W. Huang, M. Hong, X. Liu, Nat. Nanotechnol. 2015, 10, 237; c) R. Li, Z. Ji, J. Dong, C. H. Chang, X. Wang, B. Sun, M. Wang, Y.-P. Liao, J. I. Zink, A. E. Nel, T. Xia, ACS Nano 2015, 9, 3293.

[20] a) G. Chen, H. Qiu, P. N. Prasad, X. Chen, Chem. Rev. 2014, 114, 5161 ; b) D. Yang, P. a. Ma, Z. Hou, Z. Cheng, C. Li, J. Lin, Chem. Soc. Rev. 2015, 44, 1416; c) H. Dong, S.-R. Du, X.-Y. Zheng, G.-M. Lyu, L.-D. Sun, L.-D. Li, P.-Z. Zhang, C. Zhang, C.-H. Yan, Chem. Rev. 2015, 115, 10725; d) L. Cheng, C. Wang, L. Feng, 
K. Yang, Z. Liu, Chem. Rev. 2014, 114, 10869; e) M. Sun, L. Xu W. Ma, X. Wu, H. Kuang, L. Wang, C. Xu, Adv. Mater. 2016, 28, 898.

[21] L.-D. Sun, Y.-F. Wang, C.-H. Yan, Acc. Chem. Res. 2014, 47, 1001

[22] a) H. Yuan, S. Khatua, P. Zijlstra, M. Yorulmaz, M. Orrit, Angew. Chem. Int. Ed. 2013, 52, 1217; b) S. Khatua, P. M. R. Paulo, H. Yuan, A. Gupta, P. Zijlstra, M. Orrit, ACS Nano 2014, 8, 4440; c) A. Kinkhabwala, Z. Yu, S. Fan, Y. Avlasevich, K. Mullen, W. E. Moerner, Nat. Photonics 2009, 3, 654; d) P. Holzmeister, E. Pibiri, J. J. Schmied, T. Sen, G. P. Acuna, P. Tinnefeld, Nat. Commun. 2014, 5, 5356; e) A. Bek, R. Jansen, M. Ringler, S. Mayilo, T. A. Klar, J. Feldmann, Nano Lett. 2008, 8, 485.

[23] Y. Wang, T. Yang, M. T. Tuominen, M. Achermann, Phys. Rev. Lett. 2009, 102, 163001.

[24] a) W. Park, D. Lu, S. Ahn, Chem. Soc. Rev. 2015, 44, 2940; b) M. Saboktakin, X. Ye, U. K. Chettiar, N. Engheta, C. B. Murray, C. R. Kagan, ACS Nano 2013, 7, 7186; c) W. Zhang, F. Ding, S. Y. Chou, Adv. Opt. Mater. 2012, 24, 236; d) M. Saboktakin, X. Ye, S. J. Oh, S.-H. Hong, A. T. Fafarman, U. K. Chettiar, N. Engheta, C. B. Murray, C. R. Kagan, ACS Nano 2012, 6, 8758; e) Q.-C. Sun, H. Mundoor, J. C. Ribot, V. Singh, I. I. Smalyukh, P. Nagpal, Nano Lett. 2014, 14, 101.

[25] A. Kuzyk, R. Schreiber, H. Zhang, A. O. Govorov, T. Liedl, N. Liu, Nat. Mater. 2014, 13, 862.

[26] a) W. Ma, H. Kuang, L. Wang, L. Xu, W.-S. Chang, H. Zhang, M. Sun, Y. Zhu, Y. Zhao, L. Liu, C. Xu, S. Link, N. A. Kotov, Sci. Rep. 2013, 3, 1934; b) C. Zhou, X. Duan, N. Liu, Nat. Commun. 2015, 6, 8102.

[27] L. Xu, H. Kuang, C. Xu, W. Ma, L. Wang, N. A. Kotov, J. Am. Chem. Soc. 2012, 134, 1699
[28] R. Qiao, C. Liu, M. Liu, H. Hu, C. Liu, Y. Hou, K. Wu, Y. Lin, J. Liang, M. Gao, ACS Nano 2015, 9, 2120

[29] P. K. Jain, S. Eustis, M. A. El-Sayed, J. Phys. Chem. B 2006, 110, 18243.

[30] N. Berova, L. D. Bari, G. Pescitelli, Chem. Soc. Rev. 2007, 36, 914.

[31] I. Lieberman, G. Shemer, T. Fried, E. M. Kosower, G. Markovich, Angew. Chem. Int. Ed. 2008, 47, 4855.

[32] a) L. Xu, W. Yan, W. Ma, H. Kuang, X. Wu, L. Liu, Y. Zhao, L. Wang, C. Xu, Adv. Mater. 2015, 27, 1706; b) K. L. Young, M. B. Ross, M. G. Blaber, M. Rycenga, M. R. Jones, C. Zhang, A. J. Senesi, B. Lee, G. C. Schatz, C. A. Mirkin, Adv. Mater. 2014, 26, 653.

[33] B. Yeom, H. Zhang, H. Zhang, J. I. Park, K. Kim, A. O. Govorov, N. A. Kotov, Nano Lett. 2013, 13, 5277.

[34] a) T. Gibaud, E. Barry, M. J. Zakhary, M. Henglin, A. Ward, Y. Yang, C. Berciu, R. Oldenbourg, M. F. Hagan, D. Nicastro, R. B. Meyer, Z. Dogic, Nature 2012, 481, 348; b) H. Miyake, H. Tsukube, Chem. Soc. Rev. 2012, 41, 6977; c) M. Caricato, A. K. Sharma, C. Coluccini, D. Pasini, Nanoscale 2014, 6, 7165; d) M. Caricato, A. Delforge, D. Bonifazi, D. Dondi, A. Mazzanti, D. Pasini, Org. Biomol. Chem. 2015, 13, 3593

[35] Y. Zhao, L. Xu, W. Ma, L. Wang, H. Kuang, C. Xu, N. A. Kotov, Nano Lett. 2014, 14, 3908.

[36] a) X. Wu, L. Xu, W. Ma, L. Liu, H. Kuang, W. Yan, L. Wang, C. Xu, Adv. Funct. Mater. 2015, 25, 850; b) F. Lu, Y. Tian, M. Liu, D. Su, H. Zhang, A. O. Govorov, O. Gang, Nano Lett. 2013, 13, 3145.

[37] A. Rose, T. B. Hoang, F. McGuire, J. J. Mock, C. Ciracì, D. R. Smith, M. H. Mikkelsen, Nano Lett. 2014, 14, 4797.

[38] Y. W. C. Cao, R. Jin, C. A. Mirkin, Science 2002, 297, 1536. 